\title{
O mosaico de vegetação remanescente em Piraí da Serra, Campos Gerais do Paraná: uma abordagem preliminar da fragmentação natural da paisagem ${ }^{1}$
}

\author{
The mosaic of remnant vegetation in Piraí da Serra, Campos \\ Gerais, Paraná: a preliminary approach on the fragmentation \\ of landscape
}

\author{
Valquiria Martins Nanuncio \\ Universidade Estadual de Ponta Grossa \\ Rosemeri Segecin Moro \\ Universidade Estadual de Ponta Grossa
}

\begin{abstract}
Resumo: Piraí da Serra representa uma área prioritária para a preservação devido as suas características peculiares e sua localização na Escarpa Devoniana, próximo ao cânion do Guartelá. A região de 51.200 ha, com predomínio de Florestas com Araucária e campos de altitude associados pertence ao bioma Mata Atlântica, um dos mais ameaçados do Brasil. Características naturais e antrópicas promoveram a fragmentação desses habitats nativos. Com o intuito de subsidiar futuras inferências sobre tais processos, esse artigo propõe-se a caracterizar a vegetação local. Com base em dados já existentes sobre o uso da terra, foram coletadas informações em campo referente à vegetação florestal e campestre. Nas áreas de campo seco e de afloramentos rochosos foram observados 83 táxons, distribuídos entre 33 famílias; nas áreas de campos úmidos, 12 táxons em 7 famílias; e nas áreas de cerrado, 65 táxons pertencentes a 30 famílias. Nas áreas florestadas, observou-se 74 táxons em 29 famílias. A análise reforça a necessidade de medidas mitigadoras que busquem frear a progressiva fragmentação dos habitats em Piraí da Serra.
\end{abstract}

Palavras-chave: Fragmentação de habitats. Campos Gerais. Vegetação florestal. Vegetação campestre.

\begin{abstract}
Piraí da Serra, located at the Devonian Escarpment close to the Guartelá Canyon in Paraná, is an area of special interest for preservation due to its peculiar characteristics. Here, a region of 51.200 ha, covered mainly with two formations belonging to the Atlantic forest Biome - the Araucaria forest and Campos Grass Higlands - is one of the most endangered areas in Brazil. Natural features and human activities have promoted the fragmentation of these natural habitats. In order to follow up the future evolution of these processes, this paper proposes a characterization of the local vegetation. Based on previous land use data, specific information on the taxonomic and floristic situation of the forests and grasslands has been collected. In dry grassland areas and on outcroppings of rocks 83 taxa
\end{abstract}

${ }^{1}$ Este estudo integra o projeto Fragmentação da paisagem natural em Piraí da Serra, Campos Gerais do Paraná, o qual visa estabelecer os padrões de fragmentação que podem levar à proposição de formas sustentáveis de uso da terra, de novas unidades de conservação e criação de corredores de biodiversidade. 
distributed among 33 families have been observed, in moist grassland areas 12 taxa from 7 families werde found; and in savannah areas (Cerrado type) 65 taxa pertaining to 30 families. In forest areas, 74 taxa from 29 families have been documented. The analysis of the collected data reinforces the urgent need for measures which help to diminish progressive habitat fragmentation in Piraí da Serra.

Keywords: Habitat fragmentation. Campos Gerais. Forest. Grassland.

\section{INTRODUÇÃO}

Piraí da Serra, localizada na região fitogeográfica dos Campos Gerais, no Paraná, abrange três municípios: Piraí do Sul, Castro e Tibagi. Particularidades, como a proximidade com o cânion do Guartelá, e o terreno acidentado de suas terras altas, caracterizado pela expressiva presença de lineamentos, favoreceram a preservação da vegetação nativa até meados do século $X X$ (PRIETO, 2007).

A paisagem original é dominada por campos naturais, de altitude, intercalados por Florestas com Araucária que acompanham cursos de água, afloramentos rochosos e alguns ambientes de cerrado (BILENCA e MINARRO, 2004, p. 206). Estas formações vegetacionais pertencem ao Bioma Mata Atlântica, um dos mais ameaçados do Brasil.

Apesar de sua riqueza em paisagens únicas, a região é ainda pouco estudada. A integridade de sua paisagem encontra-se sob sérias ameaças pela expansão dos florestamentos com espécies exóticas, especialmente Pinus, e pela agricultura intensiva de exportação (MELO et al., 2004).

Tendo em vista a grande pressão que o agronegócio tem provocado sobre tais ecossistemas, causando supressão dos habitats nativos, o estudo da área é primordial para proporcionar condições de manejo adequadas, a partir do conhecimento da estrutura e da distribuição espacial da vegetação remanes- cente. O sucesso do manejo para áreas conservadas depende do conhecimento da ecologia da paisagem e da análise da estrutura e da dinâmica das populações que formam os fragmentos.

Desta forma, este artigo pretende apresentar a caracterização da vegetação local, em termos de espécies chave, relevo e solo, no sentido de subsidiar futuras inferências sobre processos de fragmentação de habitas da área e sua funcionalidade.

\section{BIOMA MATA ATLÂNTICA E ECOSSISTEMAS ASSOCIADOS}

O bioma Mata Atlântica é o terceiro maior bioma brasileiro com cerca de 1.110.182 km², perdendo em extensão apenas para os biomas Amazônia e Cerrado. Ocupa toda a faixa continental atlântica leste brasileira, se estendendo para o interior no Sudeste e Sul do País (IBGE, 2004).

É composto por um conjunto de formações florestais, que incluem a Floresta Ombrófila Densa, Floresta Ombrófila Mista, Floresta Ombrófila Aberta, Floresta Estacional Semidecidual, Floresta Estacional Decidual, manguezais, restingas e campos de altitude associados, brejos interioranos e encraves florestais do Nordeste. A elevação da borda continental, durante o cenozóico teria sido o fator que propiciou o aparecimento do bioma e suas paisagens (LEITE, 1994 in CASTELLA e BRITEZ, 2004), aliado as flutuações climáticas do Quaternário (AB'SABER, 2003). 
A vegetação dos Campos Gerais do Paraná pertence às áreas com domínio da Floresta Ombrófila Mista e Campos de altitude associados, do tipo Estepe gramíneo-lenhosa (VELOSO et al, 1991).

A Floresta Ombrófila Mista é uma formação adaptada a condições de clima temperado úmido (clima subtropical), de altitudes entre 500 a $1.200 \mathrm{~m}$; ocorrendo de forma contínua principalmente nos três Estados do Sul do Brasil, sendo que o Paraná apresenta a maior extensão dessa unidade fitoecológica (CASTELLA e BRITEZ, 2004).

Apresentando variações significativas dentro de sua área de distribuição, a Floresta Ombrófila Mista, pode adquirir diferentes configurações. Na região dos Campos Gerais, apresenta-se sob duas formações distintas: Floresta Ombrófila Mista Montana (FOMM) e Floresta Ombrófila Mista Aluvial (FOMA).

Formações de FOMM ocupam porções planálticas em geral, de configurações freqüentemente arredondadas, em locais bem drenados de topo e encostas, especialmente côncavas, vinculadas a latossolos, cambissolos e neossolos litólicos (OLIVIERA et al., 2003; CURCIO et al., 2006). As formações de FOMA estão associadas a cursos d'água, ocupando os terços inferiores de rampas e margens de rios, sendo normalmente vinculadas a neossolos flúvicos e a gleissolos (OLIVEIRA et al., 2003; CURCIO et al., 2006; MELO et al., 2007).

Indiferente às configurações adquiridas pela Floresta com Araucária, como o próprio nome sugere, seu elemento mais característico é a Araucaria angustifolia, uma espécie pioneira e formadora do dossel, que pode ocorrer associada a diferentes grupos de espécies.

Tendo um histórico de intensiva exploração, a Floresta com Araucária remanescente nos Campos Gerais é, em sua maioria, secundária ${ }^{2}$, como conseqüência do ciclo da erva-mate e da madeira (MELO et al., 2007). A definição de seu estágio de desenvolvimento, conforme as espécies encontradas em seu bosque, segue a resolução $n^{\circ} 002$ do CONAMA (Conselho Nacional do Meio Ambiente), de 18 de março de 1994, que dispõe sobre os estágios sucessionais e estabelece parâmetros para seu reconhecimento.

Assim, pelo artigo $2^{\circ}$, a Floresta Ombrófila Mista, pode apresentar-se em três diferentes estágios de sucessão, todos com listas de espécies comuns a eles. O estágio inicial de regeneração tem como características: fisionomia herbáceo/arbustiva, formando um estrato, variando de fechado a aberto, com a presença de espécies predominantemente heliófitas, ocorrência de espécies lenhosas (de uma até 10 espécies), com reduzidos diâmetro e altura (esta não ultrapassando 10m); o crescimento das árvores do dossel é rápido, as epífitas são raras, lianas herbáceas e gramíneas são abundantes; não há regeneração das árvores do dossel.

O estágio médio de regeneração caracteriza-se por uma fisionomia arbustiva ou arbórea (formando um ou dois estratos), com espécies lenhosas variando entre 5 e 30 táxons; dossel com altura entre 8 e 17m; epífitas são comuns; a regeneração das árvores do dossel é pequena.

O estágio avançado de regeneração compõe-se de uma fisionomia arbórea dominante sobre as demais, formando dossel fechado e uniforme, com presença de mais de dois estratos e

\footnotetext{
${ }^{2}$ Vegetação resultante dos processos naturais de sucessão, após supressão total ou parcial da vegetação primária por ações antrópicas ou causas naturais, podendo ocorrer espécies remanescentes da vegetação primária.
} 
espécies ombrófilas; as espécies lenhosas somam um número superior a 30 táxons; as árvores do dossel possuem desenvolvimento lento e vida longa; as epífitas são abundantes e as gramíneas raras; a regeneração das árvores do dossel é intensa.

Com relação aos campos, estes ocorrem em regiões areníticas planas ou plano-deprimidas (neste caso, mal drenadas), em cambissolos e neossolos litólicos e/ou regolíticos, pobres e rasos (RAMBALDI e OLIVEIRA, 2003, p. 56), ou vinculados a gleissolos e organossolos quando sujeitos à retenção hídrica permanente ou sazonal. Estas áreas estépicas são formas relictas de um antigo clima semi-árido pleistocênico, consequentemente constituem a formação florística mais antiga ou primária do Estado do Paraná. Atualmente o clima é tipicamente florestal, ou seja, existe uma tendência de expansão das florestas com Araucária sobre os campos (MAAK, 1968, p.253), mas que é pouco perceptível devido à intensividade com que o agronegócio os altera (RAMBALDI e OLIVEIRA, 2003, p.56).

As formações campestres também possuem variações fisionômicas, determinadas principalmente pelas condições edáficas. Moro e Carmo (2007, p. 94), revisando a definição dos remanescentes campestres nos Campos Gerais, os situam em três grupos: campos secos e com afloramentos rochosos, campos úmidos e cerrado.

Os campos secos (estepe stricto sen$s u)$, podendo estar acompanhados por afloramentos rochosos (refúgios vegetacionais rupestres) em rupturas de relevo ou topos de cuestas, em geral são encontrados em solos bem drenados de topos e porções superiores de rampas, especialmente as convexas. A cobertura de gramíneas é a mais conspícua, mas há grande diversidade de espécies herbáceas e arbustos baixos lenhosos de várias famílias. São comuns nos afloramentos rochosos espécies endêmicas de bromélias, orquídeas, cactos, entre outras.

Já os campos úmidos (estepe higrófila), ocorrem onde há acúmulo de água nos topos deprimidos ou nas encostas com afloramentos de lençol. Uma terceira situação de ocorrência é nos organossolos de final de rampa, junto aos cursos de água. A cobertura pode parecer de gramíneas, mas, na verdade, a família Cyperaceae é o grupo de táxons mais importante nestes locais, que também costumam abrigar espécies insetívoras (MORO et al., 2006).

A caracterização dos estágios sucessionais dos campos de altitude associados ao Bioma Mata Atlântica está sendo analisada pelo CONAMA, atendendo ao disposto na Lei $\mathrm{n}^{\circ} 11.428$, de 22 de dezembro de 2006 (Lei da Mata Atlântica), em função dos seguintes parâmetros básicos:

I - história de uso;

II - índice de cobertura do solo;

III - diversidade e dominância de espécies;

IV - espécies vegetais indicadoras;

$\mathrm{V}$ - presença de turfeiras;

VI - presença de vegetação rupestre.

Por fim, os cerrados ou formações savânicas, ocorrem nos Campos Gerais como pequenos relictos, pois a região é o limite austral dessa vegetação no Brasil, apresentando uma configuração menos densa e menos diversa do que normalmente é encontrado em áreas core de cerrado. Características de solo, relevo e elementos climáticos parecem limitar o desenvolvimento de certas espécies, que normalmente atingiriam alturas mais elevadas e maior densidade de indivíduos em latitudes menores (RITTER et al., 2007, p. 5). 


\section{FRAGMENTAÇÃO DE HABITATS}

Originalmente, a cobertura original da Floresta com Araucária no estado do Paraná era de $73.780 \mathrm{Km}^{2}$, com distribuição no Primeiro Planalto, a oeste da Serra do Mar, estendendo-se pelos Segundo e Terceiro Planaltos (MAAK, 1968, p.200).

Todavia, assim como ocorreu com outras formações florestais brasileiras, a Floresta com Araucária foi muito reduzida, resultado de um processo histórico de ocupação do solo. Hoje, restaram apenas $0,8 \%$ deste bioma em estágio avançado de sucessão, espalhadas em diversas situações de fragmentação pelo estado (CASTELLA e BRIETZ, 2004, p. 24). Pode-se definir um fragmento florestal como uma área de vegetação natural, interrompida por barreiras antrópicas (estradas, povoados, culturas agrícolas, culturas florestais, pastagens, ...) ou naturais (montanhas, lagos, represas, ou outras formações vegetais) capazes de diminuir significativamente o fluxo de espécies.

Para Rambaldi e Oliveira (2003, p.44), as situações naturais, isoladas ou combinadas entre si, que proporcionam certo grau de fragmentação à vegetação florestal, seriam: (1) flutuações climáticas, que podem causar expansão ou retração de determinados tipos de vegetação; (2) heterogeneidade de solos, com certos tipos de vegetação restritos a especificidades edáficas; (3) topografia, que pode formar ilhas de tipos específicos de vegetação em locais elevados; (4) processos de sedimentação e hidrodinâmica em rios e no mar; (5) processos hidrogeológicos que produzem áreas temporariamente ou permanentemente alagadas, onde ocorrem tipos particulares de vegetação.
No caso dos mosaicos de Estepe e Floresta com Araucária nos Campos Gerais (Figura 1), processos de fragmentação natural são freqüentes, relacionados à presença de solos rasos areníticos ou aos solos mais desenvolvidos dos diques de diabásio, com disponibilidade de água variável.

Entender os processos que levaram à fragmentação de uma dada vegetação é fundamental para propostas de conservação e/ou recuperação de qualquer área. Processos antrópicos são sempre mais impactantes negativamente, enquanto os processos naturais em geral acabam por criar situações favoráveis à biodiversidade. Assim, fragmentos naturais devem ser claramente diferenciados de fragmentos antrópicos na definição e implementação de políticas públicas de conservação; alguns fragmentos naturais constituem áreas prioritárias para conservação porque abrigam espécies endêmicas e populações diferenciadas. Além disso, para Rambaldi e Oliveira (2003, p.60), fragmentos naturais devem ser preservados como fragmentos e não devem ser conectados, pois a interligação poderia destruir a estrutura populacional e causar extinções locais; sendo importante considerar o uso e conservação do solo no entorno (matriz).

\section{MATERIAL E MÉTODO}

\section{Reconhecendo a área de estudo}

Piraí da Serra compreende uma área com cerca de 51.200 ha à margem direita da Escarpa Devoniana, abrangendo parte de três municípios: Piraí do Sul, Castro e Tibagi (Figura 2). A Escarpa Devoniana constitui uma Área de Proteção Ambiental estadual (SEMA, 


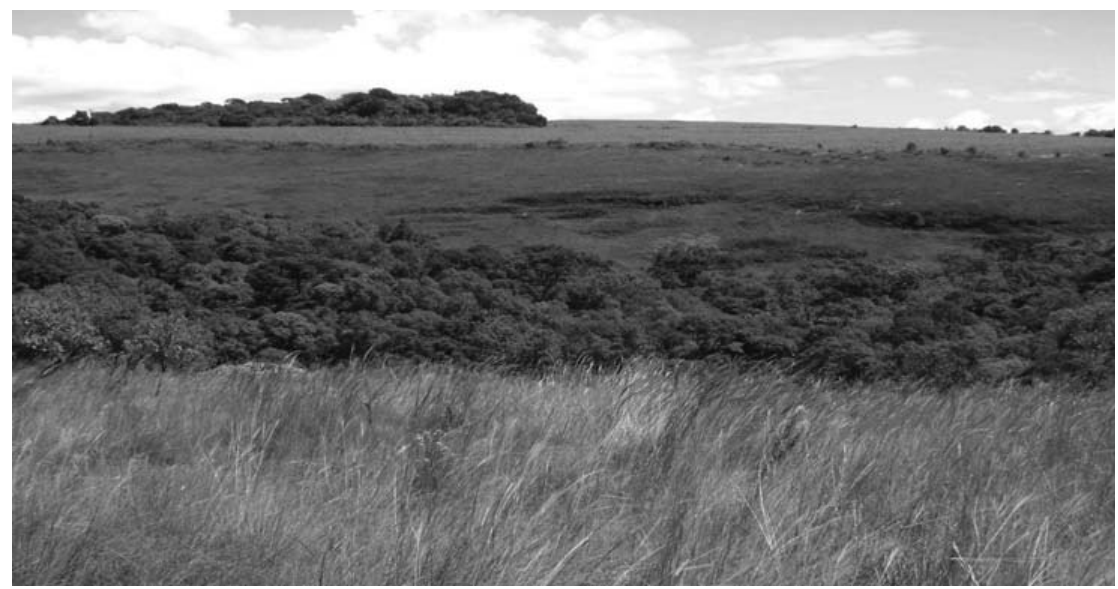

Figura 1: Mosaico vegetacional de estepe e floresta com Araucária em Piraí da Serra.

2004), onde os campos de altitude ${ }^{3}$ são mais facilmente caracterizados, sendo mantidos e, em alguns pontos, ampliados pela ação do fogo, ocorrendo também manchas de cerrado (CASTELLA e BRITEZ, 2004, p. 21).

Limita-se a sudeste pela Escarpa
Devoniana e a norte-noroeste pela margem esquerda do Rio Fortaleza, entre o Rio Guaricanga a montante e o Córrego Santo Amaro a jusante. A leste confronta com a rodovia PR 90, e a oeste com a margem direita do Rio Iapó. É atravessada por muitos canyons alongados na

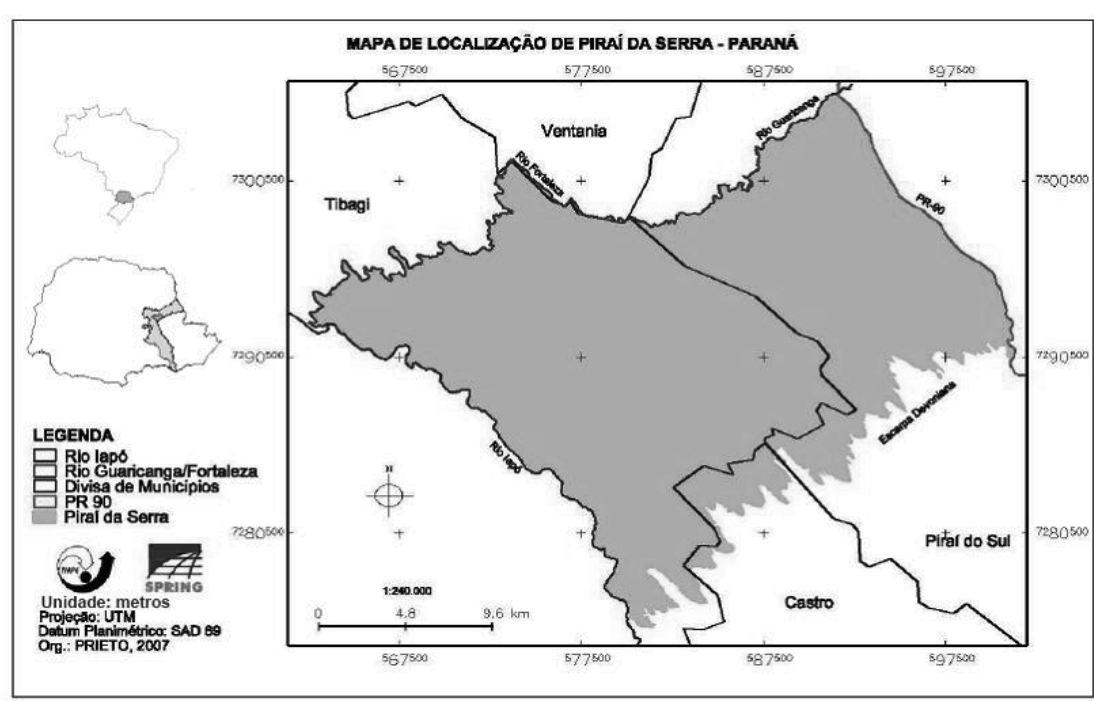

Figura 2: Mapa de localização de Piraí da Serra com relação aos municípios. (Fonte: PRIETO, 2007).

${ }^{3}$ Vegetação típica de ambientes montano e alto-montano, com estrutura arbustiva e/ou herbácea, que ocorre geralmente nos cumes litólicos das serras com altitudes elevadas, predominando em clima subtropical ou temperado. Caracteriza-se por uma ruptura na seqüência natural das espécies presentes nas formações fisionômicas circunvizinhas. As comunidades florísticas próprias dessa vegetação são caracterizadas por endemismos. direção NW-SE, propícios ao desenvolvimento de vegetação arbórea, com potencial riqueza de fauna e flora. Segundo Prieto (2007), da área total de Piraí da Serra (51.200 ha), cerca de 9.160 ha $(17,9 \%)$ é representado por Floresta com Araucária e 19.990 ha $(36,7$ $\%)$ por Estepe gramíneo-lenhosa; o restante é constituído por monocultura florestal exótica de Pinus e Eucalipto $(6,4 \%)$ e de cultivo (36,7\%), ou seja, mais de $40 \%$ da área é constituída por uma matriz antropizada. 


\section{Procedimentos}

A fim de obter maiores informações a respeito da vegetação de Piraí da Serra, foram realizadas idas a campo durante os meses de agosto de 2007 e março de 2008. O levantamento dos sítios amostrais teve como base a classificação do uso da terra realizado por Prieto (2007), tornando possível a identificação das áreas de maior interesse, devidamente georreferenciados com GPS Garmin Etrex, com cerca de $4 \mathrm{~m}$ de erro (figura 3).

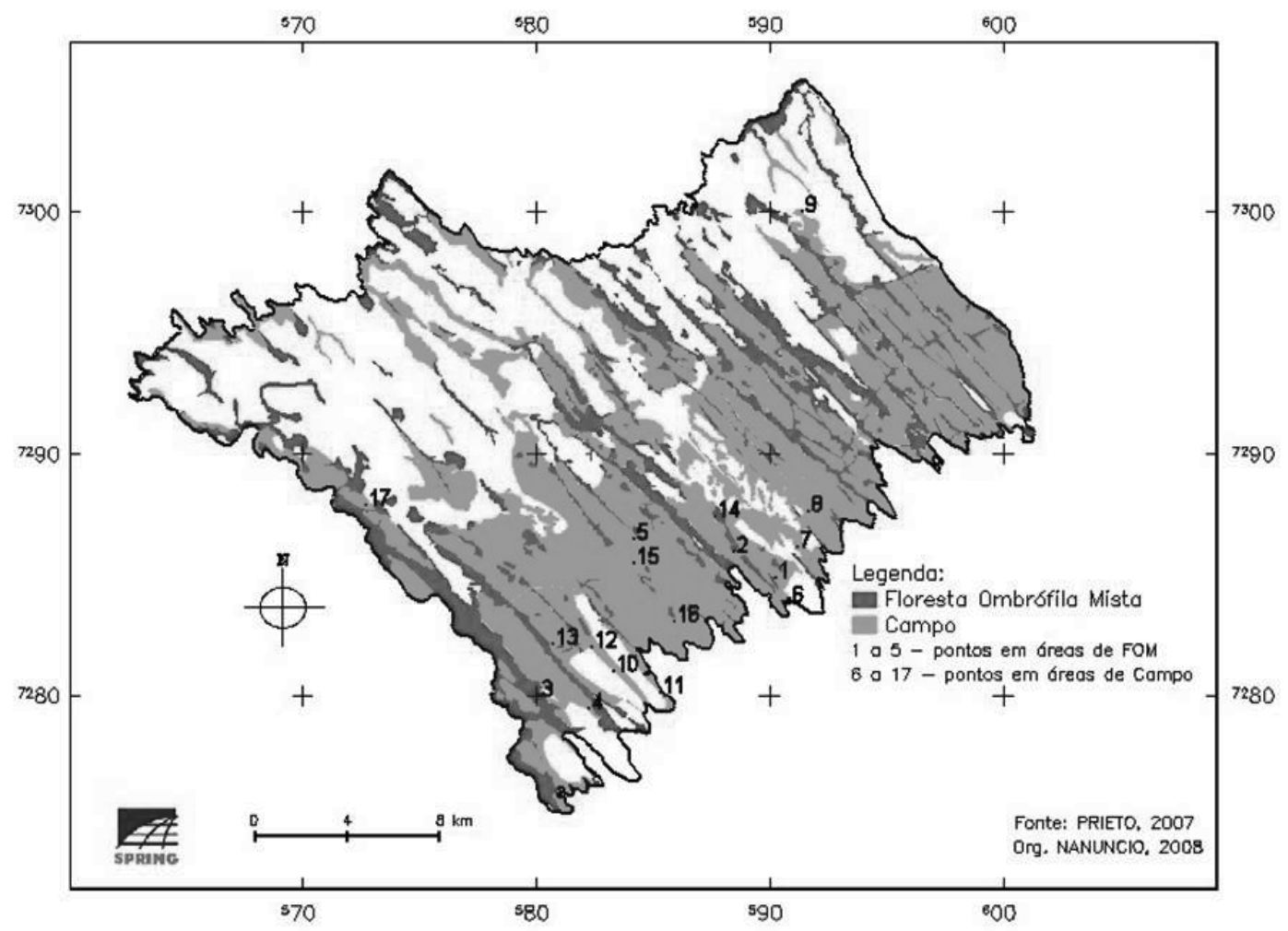

Figura 3: Distribuição espacial dos pontos de coleta em Piraí da Serra. Pontos em áreas de mata: 1 (X590723 Y7283876), 2 (X582151 Y7279448), 3 (X580622 Y7279914), 4 (X588354 Y7285907), 5 (X584076 Y7286465); pontos em áreas de campo: 6 (X590723 Y7283876), 7 (X591103 Y7286163), 8 (X591147 Y7287613), 9 (X591382 Y7300198), 10 (X584718 Y7237657), 11 (X584188 Y7278121), 12 (X582151 Y7279448), 13 (X580622 Y7279914), 14 (X588354 Y7285907), 15 (X584076 Y7286465), 16 (X585799 Y7283160), 17 (X572580 Y7288836). 


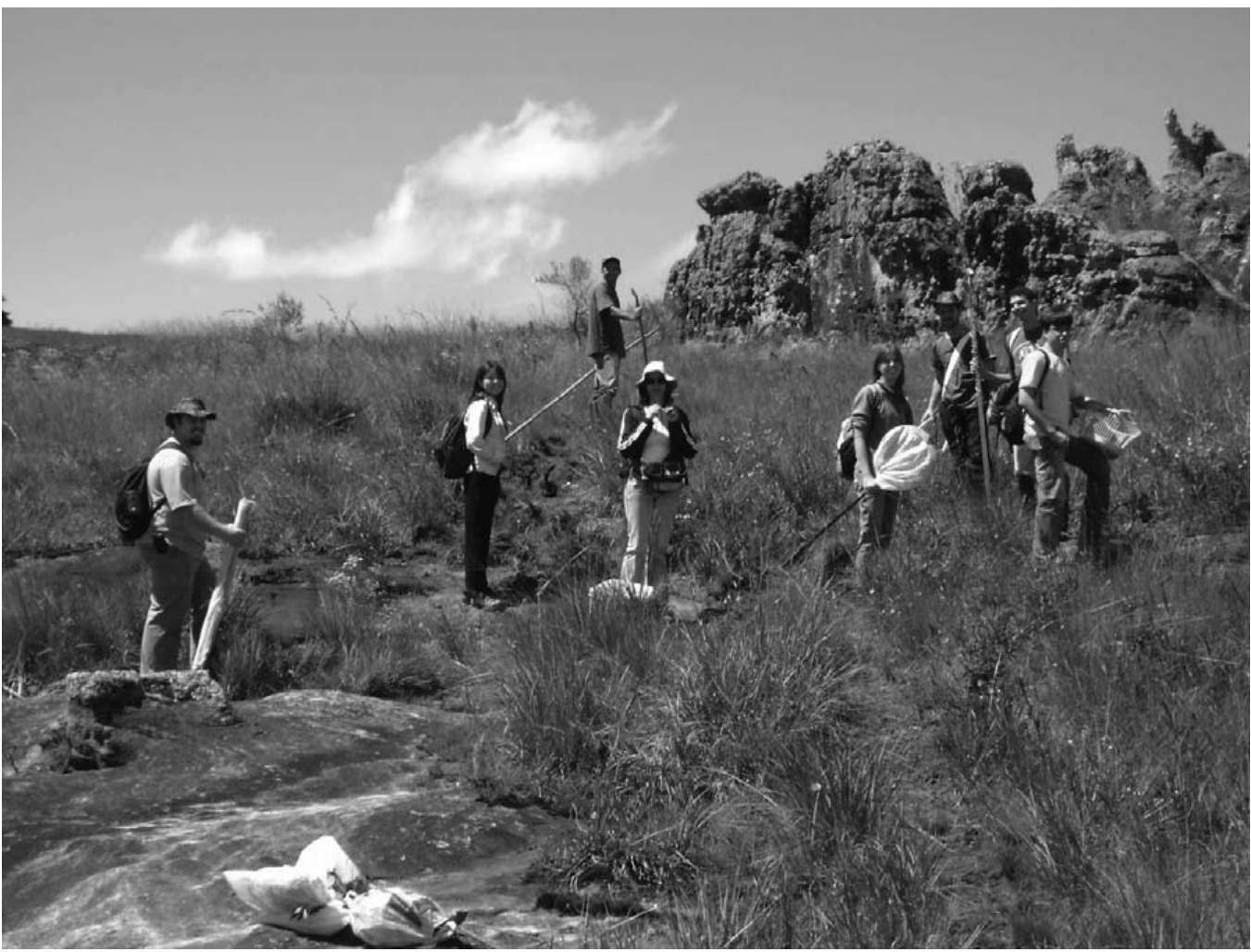

Figura 4: Equipe da UEPG coletando junto a um refúgio vegetacional rupestre em Piraí da Serra.

As espécies foram coletadas às bordas dos fragmentos, em diferentes ambientes (estepes e florestas) e de acordo com sua tipologia (Figura 4). As plantas foram processadas de acordo com as técnicas de herborização usuais e identificadas através de bibliografia especializada e por comparação com o acervo do herbário HUPG, da Universidade Estadual de Ponta Grossa. A coleta expedita das amostras se deu segundo o método de Avaliação Ecológica Rápida (SOBREVILLA e BATH, 1992). A classificação dos solos a um primeiro nível hierárquico seguiu a diretrizes da EMBRAPA (2006).

\section{RESULTADOS E DISCUSSÃO}

\section{Formações florestais}

Foram analisadas áreas pertencentes à FOMM e a FOMA, todas em estágio avançado de sucessão ecológica (tabela 1). Nos fragmentos de Floresta com Araucária estudados, foram determinados 74 táxons de 29 famílias, com maior freqüência de Asteraceae, seguida de Myrtaceae e Melastomataceae (domínio do sub-bosque) e Lauraceae (formadoras de dossel). Foram encontradas ainda espécies climácicas como a imbuia (Ocotea porosa), da família Lauraceae, e a própria Araucaria angustifolia, da família Araucariaceae, espécies ameaçadas de extinção. 
Tabela 1: Lista de táxons observados na Floresta Ombrófila Mista (FOMM e FOMA)

\begin{tabular}{|c|c|c|}
\hline FAMÍLIA & $\begin{array}{l}\text { ESPÉCIE } \\
\end{array}$ & HÁBITO \\
\hline ARAUCARIACEAE & Araucaria angustifolia $\mathrm{O}$ Kuntze & Árvore \\
\hline ARECACEAE & Syagrus romanzoffiana (Cham.) Glassman & Arvore \\
\hline \multirow{14}{*}{ ASTERACEAE } & Baccharis trimera (Less.) DC. & Erva \\
\hline & Calea pinnatifida (R. Br.) Less. & Liana \\
\hline & $\overline{\text { Emilia sagitata } \mathrm{DC}}$ & Erva \\
\hline & Eupatorium tanacaetifolium DC & Erva \\
\hline & Lucilia lycopodioides (Less.) S.E. Freire & Erva \\
\hline & Mikania hoffmanniana Dusén & Liana \\
\hline & Mikania hemisphaerica Sch. Bip. Ex Baker & Liana \\
\hline & Mutisia coccinea A. St.-Hil. & Liana \\
\hline & $\overline{M u t i s i a ~ s p}$ & Liana \\
\hline & Gochnatia sp & Arvore \\
\hline & Piptocarpha axillaris (Less.) Baker & Arvore \\
\hline & Piptocarpha regnelii (Sch. Bip.) Cabrera & Arvore \\
\hline & Senecio oligophyllus Baker & Erva \\
\hline & Vernonia mollissima D.Don & Arbusto \\
\hline \multirow[t]{2}{*}{ BIGNONIACEAE } & Indet. 1 & \\
\hline & $\begin{array}{l}\text { Indet } 2 \\
\text { Dickia tuberosa (Vell) Beer }\end{array}$ & Erva \\
\hline COMMELINACEAE & Commelina vilosa C.B. Clarke ex Chodat \& Hassl. & $\begin{array}{l}\text { Erva } \\
\text { Erva }\end{array}$ \\
\hline EUPHORBIACEAE & Sebastiana commersoniana Baill. (Sm. \& Downs) & Arvore \\
\hline ERICACEAE & Gaylussacia brasiliensis (Spreng.) Meisn. & Arbusto \\
\hline ERYTHROXILACEAE & Erythroxylum deciduum A. St.-Hil. & Arvore \\
\hline \multirow[t]{3}{*}{ FABACEAE } & Collaea speciosa (Loisel.) DC. & Erva \\
\hline & Senna multijuga (Rich.) H.S. Irwin \& Barneby & Arvore \\
\hline & Dalbergia brasiliensis Vogel & Arvore \\
\hline \multirow[t]{2}{*}{ FLACOURTIACEAE } & Casearia lasiophylla Eichler & Arvore \\
\hline & Casearia sylvestris Sw & Arvore \\
\hline GLEICHENIACEAE & Sticherus penniger (Mart.) Copel. & Erva \\
\hline IRIDACEAE & Sisyrinchium wettsteinii Hand Mazz & Erva \\
\hline LAMIACEAE & Salvia melissaefolia Desf. & Erva \\
\hline \multirow{7}{*}{ LAURACEAE } & Cinnamomum sellowianum Kosterm. & Arvore \\
\hline & Endlicleria paniculata (Spreng.) J.F. Macbr. & Arvore \\
\hline & Nectandra grandiflora Nees \& C. Mart. ex Nees & Arvore \\
\hline & Ocotea diospyrifolia (Meisn.) Mez & Arvore \\
\hline & Ocotea porosa (Nees \& C. Mart.) Barroso & Arvore \\
\hline & Ocotea sp & Arvore \\
\hline & Ocotea pulchella Mart. & Arvore \\
\hline \multirow[t]{5}{*}{ MELASTOMATACEAE } & Leandra simplicicaulis Cogn. & Erva \\
\hline & Miconia cinerascens Miq. & Arbusto \\
\hline & Miconia hyemalis St Hill \& Naud ex Naud & Arvore \\
\hline & Miconia sellowiana Naud. & Arbusto \\
\hline & Tibouchina martialis (Cham.) Cogn. & Erva \\
\hline \multirow[t]{3}{*}{ MIMOSACEAE } & Anadenanthera collubrina (Vell.) Brenan & Arvore \\
\hline & Mimosa orthoacantha Benth. & Arbusto \\
\hline & Mimosa scabrella Benth. & Arvore \\
\hline \multirow[t]{2}{*}{ MONIMIACEAE } & Mollinedia clavigera Tul. & Arbusto \\
\hline & $\overline{\text { Mollinedia elegans Tul. }}$ & Arbusto \\
\hline \multirow[t]{9}{*}{ MYRTACEAE } & Calyptranthes concinna DC & Arbusto \\
\hline & Eugenia pitanga (O. Berg) Kiaersk. & Arvore \\
\hline & Myrcia arborescens O. Berg & Arvore \\
\hline & Myrcia breviramis (O. Berg) D. Legrand & Arbusto \\
\hline & Myrcia venulosa DC & Arvore \\
\hline & Myrcia obtecta (Berg) Kiaresk & Arbusto \\
\hline & Myrciaria tenella (DC.) O. Berg & Arbusto \\
\hline & Campomanesia xanthocarpa O. Berg & Arvore \\
\hline & Indet. 1 & Arvore \\
\hline MYRSINACEAE & Myrsine umbelata (Mart) Mez & Arvore \\
\hline PIPERACEAE & Peperomia catharinae Miq. & Erva \\
\hline PLANTAGINACEAE & Plantago tomentosa Lam. & Erva \\
\hline RHAMNACEAE & Rhamnus sectipetala Mart. ex Reissek & Arvore \\
\hline \multirow[t]{3}{*}{ ROSACEAE } & Rubus urticifolius Poir. & Arbusto \\
\hline & Prunus sellowii Koehne & Arvore \\
\hline & Prunus myrtifolia (L.) Urb. & Arvore \\
\hline RUBIACEAE & Borreria poaya (A St Hil) DC & Erva \\
\hline SAPINDACEAE & Matayba elaeagnoides Radlk. & Arvore \\
\hline & Paullinia carpopoda Cambess. & Liana \\
\hline SOLANACEAE & Nicotiana sp & Erva \\
\hline & Petunia linoides Sendtn. & Erva \\
\hline & Solanum lacerdae Dusen & Arvore \\
\hline & Calibrachoa ericifolia (R.E.Fr.) Wijsman & Erva \\
\hline THEACEAE & Laplacea fruticosa (Schrad.) Kobuski & Arvore \\
\hline THYMELLAEACEAE & Daphnopsis beta Taub. & Arvore \\
\hline & Daphnopsis fasciculata (Meisn.) Nevling & Arvore \\
\hline Total de famílias: 29 & Total de táxons: 74 & \\
\hline
\end{tabular}


A Floresta com Araucária em Piraí da Serra encontra-se geralmente associada a duas situações:

a) a alinhamentos esculturais, de forte controle estrutural, de origem tectônica. Nos vales mais encaixados há a ocorrência de afloramentos rochosos e neossolos litólicos, com acesso limitado à floresta. Esta se instala ao fundo destes canyons em função do grau de intemperismo da rocha e da intensidade dos processos de esculturação. Como é freqüente este entalhamento através do regime hídrico, os ambientes ripários formados podem originar latossolos profundos capazes de suportar uma floresta complexa multiestratificada.

b) encostas com boa drenagem, predominantemente com cambissolos, ocasionalmente latossolos nos topos de interflúvios. A floresta ocupa os terços médios e finais destas rampas em função da profundidade do solo, do contrário cederá lugar a estepe sensu stricto.

\section{FORMAÇÕES CAMPESTRES}

Os compartimentos fitofisionômicos dos campos estão ligados a diversos fatores, os quais podem ser resumidos em a) sazonalidade do regime hídrico do solo e seu grau de saturação, relacionados à posição que ocupam na encosta, bem como forma e declividade da rampa; b) altitude; c) espessura do solo, textura e forma de contato com a rocha. A combinação desses elementos pode resultar em escoamentos hídricos distintos - laterais e verticais, os quais são determinantes não somente para a presença de algumas espécies, como também para a formação de mosaicos tipológicos (CURCIO et al., 2006).

Quanto aos fragmentos de campos nativos, as áreas de campo seco e com afloramentos rochosos (tabela 2) foram os que apresentaram maior número de táxons (83), distribuídos entre 33 famílias, onde as mais representativas foram Asteraceae e Poaceae, com destaque especial para Bromeliaceae, Droseraceae, Amaryllidaceae e Iridaceae, evidenciando a grande diversidade de tais ambientes.

Nas áreas de campos úmidos (tabela 3), identificou-se 12 táxons distribuídos em 7 famílias. A família com maior número de espécimes, novamente é Asteraceae, sendo representativa também Cyperaceae, pouco coletada pela falta de material fértil.

Devido à relativa inexistência de parâmetros para determinar o estágio sucessional de campos de altitude, esta análise foi feita por comparação com o acervo do herbário HUPG, sobre outras áreas reconhecidamente conservadas nos campos Gerais. No caso de vegetação primária de campos de altitude, a vegetação de máxima expressão local não necessariamente está associada à grande diversidade biológica, devido às características locais de clima, relevo, solo e vegetação adjacente.

$\mathrm{O}$ relicto de cerrado, embora pequeno em área, constitui amostra expressiva de uma vegetação que já foi predominante no Sul do Brasil (tabela 4). Das 30 famílias (total de 65 táxons), foram identificadas espécies bem características pertencentes às famílias Asteraceae, Erythroxylaceae, Mimosaceae, Melastomataceae, Vochysiaceae e Caryocaraceae.

\section{CONSIDERAÇÕES FINAIS}

A fragmentação natural da paisagem em Piraí da Serra é determinada principalmente por fatores geomórficos e paleoclimáticos, que retardaram seu 
Tabela 2: Lista de táxons observados na estepe sensu stricto e nos refúgios vegetacionais rupestres.

\begin{tabular}{|c|c|}
\hline \multicolumn{2}{|c|}{ CAMPOS SECOS } \\
\hline $\begin{array}{r}\text { FAMÍLIA } \\
\end{array}$ & ESPÉCIE \\
\hline AMARYLLIDACEAE & Hippeastrum psittacinum Herb \\
\hline ARECACEAE & Allagoptera campestris (Mart) Kuntze \\
\hline ASTERACEAE & $\begin{array}{l}\text { Aspilia setosa Griseb } \\
\text { Baccharis dracunculifolia DC } \\
\text { Calea parvifolia Bak } \\
\text { Eupatorium tanacetifolium DC }\end{array}$ \\
\hline BORRAGINACEAE & Moritzia dusenii I M Johnst \\
\hline BROMELIACEAE & Dickia tuberosa (Vell.) Beer \\
\hline DROSERACEAE & Drosera communis A. St.-Hil. \\
\hline FABACEAE & $\begin{array}{l}\text { Eriosema heterophylum Benth } \\
\text { Sthylosanthes acuminata M.B. Ferr \& S. Costa }\end{array}$ \\
\hline $\begin{array}{l}\text { IRIDACEAE } \\
\text { LAMIACEAE }\end{array}$ & $\begin{array}{l}\text { Sisyrinchium wettsteinii Hand Mazz } \\
\text { Peltodon radicans Pohl } \\
\text { Salvia sp }\end{array}$ \\
\hline MALVACEAE & $\begin{array}{l}\text { Sida macrodon DC } \\
\text { Pavonia speciosa Kunth }\end{array}$ \\
\hline MELASTOMATACEAE & $\begin{array}{l}\text { Chaetostoma pungens DC. } \\
\text { Lavoisiera phyllocalycina Cogn. } \\
\text { Lavoisiera pulchella Cham }\end{array}$ \\
\hline POLYGALACEAE & Polygala $s p$ \\
\hline POACEAE & $\begin{array}{l}\text { Panicum sp } \\
\text { Eriochysis cayennensis P. Beanv. } \\
\text { Andropogon macrothrix Trin. } \\
\text { indet. } 1\end{array}$ \\
\hline RUBIACEAE & Borreria poaya (A St Hil) DC \\
\hline SCROPHULARIACEAE & Esterhazya splendida Mikan \\
\hline STERCULIACEAE & Waltheria douradinha A St Hil \\
\hline VERBENACEAE & $\begin{array}{l}\text { Verbena hirta Spr } \\
\text { Duranta vestita Cham. } \\
\text { Lippia lupulina Cham. }\end{array}$ \\
\hline \multicolumn{2}{|c|}{ CAMPOS ROCHOSOS } \\
\hline $\begin{array}{l}\text { FAMÍLIA } \\
\text { ACANTHACEAE }\end{array}$ & \begin{tabular}{l}
\multicolumn{1}{c}{ ESPÉCIE } \\
Dyschoriste hygrophyllodes (Nees) Kunth. \\
Ruellia multifolia (Nees) Lindau
\end{tabular} \\
\hline APOCYNACEAE & Macrosiphonia sp \\
\hline ASTERACEAE & $\begin{array}{l}\text { Aspilia setosa Griseb } \\
\text { Calea parvifolia (DC.) Baker } \\
\text { Chaptalia graminifolia Dusén } \\
\text { Chrysolaena oligophylla (Vell.) H. Rob. } \\
\text { Eupatorium betonicaeforme (DC.) Baker } \\
\text { Vernonia brevifolia Less. } \\
\text { Vernonia macrocephala Less. } \\
\text { Vernonia mollissima D.Don } \\
\text { Vernonia sp } \\
\text { Vernonanthura chamaedrys (Less.) H. Rob. } \\
\text { Indet } 1 \\
\text { Indet } 2 \text {. }\end{array}$ \\
\hline AMARANTHACEAE & Pfaffia jubata Mart. \\
\hline CYPERACEAE & $\begin{array}{l}\text { Fimbristylis cf diphylla Vahl. } \\
\text { Lagenocarpus rigidus (Kunth) Nees }\end{array}$ \\
\hline ERICACEAE & Gaylussacia brasiliensis (Spreng.) Meisn. \\
\hline ERIOCAULACEAE & Paepalanthus planifolius (Bong.) Körn. \\
\hline EUPHORBIACEAE & Croton antisyphiliticus Mart. \\
\hline FABACEAE & $\begin{array}{l}\text { Eriosema heterophylum Benth } \\
\text { Periandra mediterranea (Vell) Taub }\end{array}$ \\
\hline GESNERIACEAE & Sinningia canescens (Mart) Wiehler \\
\hline IRIDACEAE & $\begin{array}{l}\text { Cipura } \\
\text { Sisyrinchium iridifolium Kunth. } \\
\text { Sisyrinchium fasciculatum Klatt }\end{array}$ \\
\hline LAMIACEAE & $\begin{array}{l}\text { Salvia rosmarinoides A. St.-Hil. ex Benth. } \\
\text { Peltodon radicans Pohl }\end{array}$ \\
\hline MALVACEAE & Pavonia sepium A. St.Hill. \\
\hline MALPIGHIACEAE & Byrsonima brachybotrya Nied. \\
\hline MELASTOMATACEAE & $\begin{array}{l}\text { Leandra dusenii Cogn. } \\
\text { Leandra lacunosa Cogn. } \\
\text { Miconia cinerascens Miq. } \\
\text { Miconia hyemalis St Hill \& Naud ex Naud }\end{array}$ \\
\hline MIMOSACEAE & $\begin{array}{l}\text { Mimosa invisa Mart. } \\
\text { Mimosa micropteris Benth } \\
\text { Mimosa orthoacantha Benth. }\end{array}$ \\
\hline MYRTACEAE & Myrcia venulosa DC. \\
\hline
\end{tabular}




\begin{tabular}{ll}
\hline OXALIDACEAE & Oxalis martiana Zucc. \\
\hline POACEAE & Axonopus marginatus (Trin.) Chase \\
& Axonopus siccus (Nees) Kuhlm. \\
& Axonopus sp \\
& Indet. 1 \\
& Paspalum pectinatum Nees ex Trin. \\
\hline POLYGALACEAE & Monnina cardiocarpa A. St.-Hil. \\
\hline RHAMNACEAE & Rhamnus sectipetala Mart. ex Reissek \\
\hline ROSACEAE & Prunus myrtifolia (L.) Urb. \\
\hline RUBIACEAE & Borreria poaya (A St Hil.) DC \\
& Indet. 1 \\
& indet. 2 \\
\hline SOLANACEAE & Nicotiana langsdorfii Nees \\
\hline VERBENACEAE & Verbena hirta Spreng \\
\hline Total de famílias: $\mathbf{3 3}$ & Total de táxons: 83
\end{tabular}

Tabela 3: Lista de táxons observados na estepe higrófila.

\begin{tabular}{ll}
\hline \multicolumn{1}{c}{ FAMÍLIA } & \multicolumn{1}{c}{ ESPÉCIE } \\
\hline ASTERACEAE & $\begin{array}{l}\text { Vernonia obovata Less. } \\
\text { Chaptalia integerrima (Vell.) Burkart } \\
\text { Chaptalia sp } \\
\text { Hypochoeris gardneri } \\
\text { Invlopsis scapura (DC) O. Hoffm }\end{array}$ \\
\hline BIGNONIACEAE & Indet. 2 \\
\hline CYPERACEAE & Rhynchospora globosa Roem. Et Schult \\
\hline ERIOCAULACEAE & $\begin{array}{l}\text { Indet. } \\
\text { Indet. }\end{array}$ \\
\hline GLEICHENIACEAE & Dicranopteris linearis (Burm. f.) Underw. \\
\hline IRIDACEAE & Sisyrinchium fasciculatum Klatt \\
\hline POACEAE & Andropogon microstachyus Desv. ex Ham. \\
\hline Total de famílias: 7 & Total de táxons: 12 \\
\hline
\end{tabular}

Tabela 4: Lista de táxons observados no relicto de cerrado (savana).

\begin{tabular}{|c|c|c|}
\hline FAMÍLIA & ESPÉCIE & НÁBITO \\
\hline AMARYLLIDACEAE & Hippeastrum psittacinum Herb & Erva \\
\hline ANACARDIACEAE & Lithraea molleoides (Vell.) Engl. & Arvore \\
\hline \multirow[t]{2}{*}{ ARECACEAE } & Allagoptera campestris (Mart) Kuntze & Arbusto \\
\hline & Syagrus romanzoffiana (Cham.) Glassman & Arvore \\
\hline \multirow[t]{10}{*}{ ASTERACEAE } & Invlopsis scapura (DC) O. Hoffm & Erva \\
\hline & Aspilia setosa Griseb & Erva \\
\hline & Baccharis dracunculifolia DC & Erva \\
\hline & Calea hispida (DC.) Baker & Erva \\
\hline & Chaptalia graminifolia Dusén & Erva \\
\hline & Chaptalia integerrima (Vell.) Burkart & Erva \\
\hline & Emilia sagittatta DC & Erva \\
\hline & Eupatorium tanacetifolium DC & Erva \\
\hline & Vernonia cuneifolia Gardner & Erva \\
\hline & $\overline{\text { Vernonia mollissima D.Don }}$ & Arbusto \\
\hline BIGNONIACEAE & Tabebuia ochraceae (Cham) Stand & Arvore \\
\hline \multirow[t]{4}{*}{ BROMELIACEAE } & Tillandsia tenuifolia $\mathrm{L}$ & Erva \\
\hline & Tillandsia tenuifolia $\mathrm{L}$. & Erva \\
\hline & Aechmea distichantha Lemaire & Erva \\
\hline & Dickia tuberosa (Vell) Beer & Erva \\
\hline CACTACEAE & Cereus jamacaru DC. & Erva \\
\hline CAESALPINACEAE & Copaifera langsdorffii Desv. & Árvore \\
\hline CAMPANULACEAE & Wahlenbergia linarioides (Lam) A DC & Erva \\
\hline CARYOCARACEAE & Caryocar brasiliense Camb. & Arbusto \\
\hline CLUSIACEAE & Hypericum brasiliensis Choisy & Erva \\
\hline CUSCUTACEAE & Cuscuta racemosa Mart & Trepadeira \\
\hline CYPERACEAE & Scleria hirtella Sw & Erva \\
\hline \multirow[t]{2}{*}{ EUPHORBIACEAE } & Alchornea triplinervia (Spreng) Muell. Arg. & Árvore \\
\hline & Croton antissiphyliticus Muell Arg & Erva \\
\hline \multirow[t]{2}{*}{ ERYTHROXYLACEAE } & Erythroxylum suberosum A.St.hill. & Árvore \\
\hline & Erythroxylum deciduum A. St.Hill. & Árvore \\
\hline
\end{tabular}


O mosaico de vegetação remanescente em Piraí da Serra, Campos Gerais do Paraná: ...

\begin{tabular}{|c|c|c|}
\hline FABACEAE & $\begin{array}{l}\text { Acosmium subelegans (Mohlenbr) Yakovlev } \\
\text { Eriosema obovatum Benth } \\
\text { Rhynchosia corydifolia Mart. } \\
\text { Periandra mediterranea Vell. (Taub.) }\end{array}$ & $\begin{array}{l}\text { Arbusto } \\
\text { Erva } \\
\text { Erva } \\
\text { Erva }\end{array}$ \\
\hline FLACOURTIACEAE & Casearia sylvestris Sw. & Árvore \\
\hline IRIDACEAE & Sisyrinchium vaginatum Spr & Erva \\
\hline LAMIACEAE & $\begin{array}{l}\text { Hyptis glauca St Hill } \\
\text { Eriope macrostachya Mart e Benth } \\
\text { Peltodon radicans Pohl } \\
\text { Salvia nervosa Benth. }\end{array}$ & $\begin{array}{l}\text { Erva } \\
\text { Erva } \\
\text { Erva } \\
\text { Erva }\end{array}$ \\
\hline MELASTOMATACEAE & $\begin{array}{l}\text { Acisanthera variabilis (DC) Triana } \\
\text { Chaetostoma pungens DC. } \\
\text { Lavoisiera phyllocalycina Cogn } \\
\text { Lavoisiera pulchella Cham. } \\
\text { Miconia albicans (Sw.) Triana } \\
\text { Miconia theaezans (Bonpl.) Cogn. } \\
\text { Miconia sellowiana Naud. } \\
\text { Tibouchina hatschbachii Wurdack } \\
\text { Tibouchina sp }\end{array}$ & $\begin{array}{l}\text { Erva } \\
\text { Erva } \\
\text { Erva } \\
\text { Erva } \\
\text { Erva } \\
\text { Árvore } \\
\text { Árvore } \\
\text { Erva } \\
\text { Erva }\end{array}$ \\
\hline MIMOSACEAE & $\begin{array}{l}\text { Stryphnodendron adstringens (Mart.) Cov. } \\
\text { Pithecellobium langsdorffii Benth. }\end{array}$ & $\begin{array}{l}\text { Arvore } \\
\text { Arvore }\end{array}$ \\
\hline MYRTACEAE & $\begin{array}{l}\text { Campomanesia pubescens (A DC) O Berg } \\
\text { Gomidesia sellowiana O. Berg. } \\
\text { Myrcia obtecta (Berg) Kiaresk }\end{array}$ & $\begin{array}{l}\text { Árvore } \\
\text { Arvore } \\
\text { Arbusto }\end{array}$ \\
\hline MYRSINACEAE & Myrsine umbellata (Mart.) Mez. & Árvore \\
\hline RHAMNACEAE & Rhamnus sectipetala Mart. ex Reissek & Arvore \\
\hline OCHNACEAE & Ouratea spectabilis (Mart.) Engl. & Árvore \\
\hline ORCHIDACEAE & Epidendron ellipticum Graham & Erva \\
\hline POACEAE & $\begin{array}{l}\text { Andropogon leucostachyus Kunth } \\
\text { Aristida jubata (Arechav.) Herter } \\
\text { Axonopous siccus (Nees) Kuhlm }\end{array}$ & $\begin{array}{l}\text { Erva } \\
\text { Erva } \\
\text { Erva }\end{array}$ \\
\hline SMILACACEAE & Smilax sp & Trepadeira \\
\hline SOLANACEAE & Petunia rupestris Dusén & Erva \\
\hline VERBENACEAE & $\begin{array}{l}\text { Verbena hirta Spr } \\
\text { Lippia lupulina Cham. }\end{array}$ & $\begin{array}{l}\text { Erva } \\
\text { Erva }\end{array}$ \\
\hline Total de famílias: 30 & Total de táxons: 65 & \\
\hline
\end{tabular}

reafeiçoamento antrópico até meados do século passado.

Em que pese o componente florestal ter sido descaracterizado, principalmente pela extração de lenha, retirada seletiva de espécies com valor econômico ou para utilização dentro da propriedade rural, a maioria dos fragmentos florestais analisados encontra-se em estágio avançado de sucessão ecológica. Mas foram observadas também áreas perturbadas, em estágio inicial de sucessão, característica facilmente observável pela grande quantidade de bioindicadores como a bracatinga (Mimosa scrabella) e vassourão-preto (Vernonia discolor).

Os resultados levantados até o momento revelam ambientes ainda preservados, reforçando a necessidade de medidas mitigadoras que busquem frear a supressão de habitats através da devastação da vegetação natural em Piraí da Serra.

Este trabalho, de caráter preliminar, não pretende apresentar uma lista florística dos ambientes de Piraí da Serra, mas apenas apontar, pela análise de espécies chave, a presença de fitotipias representativas dos ecossistemas constantes desta região fitogeográfica do bioma Mata Atlântica. Estas informações podem subsidiar posteriores discussões acerca da funcionalidade de ecossistemas naturalmente fragmentados.

\section{REFERÊNCIAS BIBLIOGRÁFICAS}

AB'SABER, A. N. Os domínios da natureza no Brasil: potencialidades paisagísticas. São 
Paulo: Ateliê Editorial, 2003.159p.

BILENCA, D.N.; MINARRO, F. Identificación de áreas valiosas de pastizal (AVPs) em las Pampas y campos de Argentina, Uruguay y sur de Brasil. Buenos Aires: FVSA, 2004. $352 p$

CASTELLA, P.R.; BRITEZ, R.M. (Org.) A floresta com araucária no Paraná: conservação e diagnóstico dos remanescentes florestais. Brasília: MMA, 2004. 236p.

CONAMA. Resolução n.002 de 18 de março de 1994. Disponível em: <www.lei.adv.br/002-94. $\mathrm{htm}>$ acesso em 26/10/2007.

CURCIO, G.R.; BONNET, A.; PESTANA, D.; SOUZA, L.; SOCHER, L.G.; GALVÃO, F.; RODERJAN, C.V. Compartimentação topossequencial e caracterização fitossociológica de um capão de Floresta ombrófila Mista. Floresta, Curitiba, v. 36, n. 3, p. 361-369, set./ dez. 2006.

EMBRAPA. Centro Nacional de Pesquisa de Solos. Sistema brasileiro de classificação de solos. 2. ed. Rio de Janeiro: Embrapa Solos, 2006. 306p

IBGE - INSTITUTO BRASILEIRO DE GEOGRAFIA E ESTATÍSTICA. Biomas brasileiros. Brasília, 2004. Disponível em: <www.ibge.com. br>. Acesso em: 05/11/2007.

MAACK, R. Geografia física do Paraná. 2 ed. Curitiba: FUNDEPAR, 1968.

MELO, M.S. de; MATIAS, L.F.; GUIMARÃES, G.B.; CRUZ, G.C.F. da; BARBOLA, I.F.; GEALH, A.M.; MORO, R.S.; AYUB, C.L.S.C.; MORO, P.R.; MOREIRA, J.C. "Piraí da Serra proposta de nova Unidade de Conservação nos Campos Gerais do Paraná." Publicatio UEPG, v.10, n.3/4, p.85-94, set./dez. 2004.

MELO, M.S.; MORO, R.S.; GUIMARÃES, G.B. Patrimônio natural dos Campos Gerais do Paraná. Ponta Grossa: Editora UEPG, 2007. 230p.

MORO, R.S.; IURK, M.C.; RITTER, L.M.O. “Vegetação ripária herbácea de uma lagoa em Carambeí, Campos Gerais do Paraná". In: CONGRESSO NACIONAL DE BOTÂNICA, 57, 2006, Gramado. Resumos .... Porto Alegre: SBB/ UFRGS, 2006.

MORO, R.S.; CARMO, M.R.B. do. A vegetação campestre. In: MELO, M.S.; MORO, R.S.; GUI-
MARÃES, G.B. Patrimônio natural dos Campos Gerais do Paraná. Ponta Grossa: Editora UEPG, 2007. p.230.

OLIVEIRA, E.A. de; RODERJAN, C.V.; CURCIO, G.R.; SILVA, S.M. “Caracterização florística, fitossociológica e pedológica de um trecho de floresta ripária dos Campos Gerais do Paraná." Cad.biodivers., v.4, n.1, p. 8-25, jan. 2003.

PRIETO, C. C. Análise da dinâmica do uso da terra sobre o patrimônio natural de Píraí da Serra - Paraná. Ponta Grossa, 2007. Monografia (Bacharelado em Geografia). Universidade Estadual de Ponta Grossa.

RAMBALDI, D.M., OLIVEIRA, D.A.S. Fragmentação de ecossistemas: causas, efeitos sobre a diversidade e recomendações de políticas públicas. Brasília: MMA/SBF, 2003. 100p.

RITTER, L.M.O.; ALMEIDA, C.G.; NANUNCIO, V.M.; MORO, R.S. Caracterização florística e fitofisionômica de um fragmento de cerrado em Carambeí, região dos Campos Gerais, PR. In: SIMPÓSIO ESTADUAL DA PÓS-GRADUAÇÃO EM GEOGRAFIA DO PARANÁ, 2, 2007, Londrina. Anais. Londrina: UEL, 2007. v. 1. (CD).

SEMA/ IAP. Plano de manejo área de proteção ambiental da escarpa devoniana. Curitiba, 2004.

SOBREVILLA, C.; BATH, P. Evaluación ecológica rápida: un manual para usuários de América Latina y el Caribe. Washington: The Nature Conservancy, 1992.

VELOSO, H.P.; RANGEL FILHO, A.L.; LIMA, J.C.A. Classificação da vegetação brasileira, adaptada a um sistema universal. Rio de Janeiro: IBGE, 1991. 123p.

(Recebido em 13/01/2008 e aceito para publicação em 20/06/2008) 